\title{
Bio-metaphor in Iraqi architecture (date palm as model)
}

\author{
Fawzia Irhayyim Al-Assadi \\ College of Engineering, Architectural Department, Baghdad University, Baghdad, Iraq. \\ Corresponding Author:fawziaasadi@coeng.uobaghdad.edu.iq
}

$\begin{array}{ll}\text { Submitted } & : 16 / 09 / 2020 \\ \text { Revised } & : 23 / 01 / 2021 \\ \text { Accepted } & : 10 / 02 / 2021\end{array}$

\begin{abstract}
The Bio-metaphor concept plays a significant role in architectural design process, by employing diverse specific organism sources like a plants or animals. The metaphor was an essential source for many architects in their achievements throughout the ages. So, plants have represented one of the inspiration sources of metaphor in architecture. From that point, the general goal of this research is to study the bio-metaphor from date palm tree in Iraqi architecture, and the effect of the morphology of this tree on Iraqi architects, and thus its effect on production.

This research deals specifically and practically with employing the concept of metaphor in Iraqi architecture throughout the ages, by studying models of various buildings from different stages of the Mesopotamian civilization, starting from the Sumerian to contemporary period of Iraqi architecture. From all of the above, the main problem that this research deals with is "the unclear approach of employing bio-metaphor "date palm tree" in specific" in Iraqi architecture.

Accomplishing the methodology of this research lies in two points. First is studying the rules which govern metaphor in architecture in general. Second is extracting the indicators of the theoretical framework and then applying them to various buildings for different periods of Mesopotamia civilization. The most prominent results reached by this research was "bio metaphor used palm tree in different ways and methods including structural and decorative aspect". So, the metaphor that relates to the structural aspect is stronger than the metaphor that relates to the ornamental aspect. Because the first will be within the morphology of the building, while the second is just final addition to the façade of the building.
\end{abstract}

Keywords: Metaphor; Bio-metaphor; Date palm; Iraqi architecture; Morphology; Mesopotamia.

\section{INTRODUCTION}

Throughout the history of architecture, the metaphor has been an important source of inspiration for many architects, related to the innovation concept and architectural changes. This is highlighted by the multiplicity of references that linked metaphor to the process of architectural design and its density. 
Metaphor is a word or phrase for one thing that is used to refer to another thing in order to show or suggest that they are similar, an object, activity, or idea that is used as a symbol of something else (GECAS, 2014). A metaphor is a figure of speech containing an implied comparison. With metaphors, words or phrases that are ordinarily applied to one thing are applied to something you wouldn't necessarily pair it with. Greene was describing metaphor as transfer or transmission of signals from one thing to another or seeing something in something else. This includes a comparison between the first and other things that are invoked to complete the comparison (Greene, 1976). While McGinty has defined the metaphor as the determination of relationships between things, these relations are characterized by being more abstract than literal (McGinty, 1979). Bio-metaphor can be defined as a process of inspiration from nature to extract solutions, which are then transferred to architecture by devising strategies for design and application, with the aim of adaptation and taking the economic factor into consideration based on the common language between nature and architecture (Al- Ahmar, 2011). Also, biometaphor in architecture is a discipline to gain innovation by using natural models, and the comparison between animate nature and built environment which is to create new insights (Gruber, 2011).

The research hypothesis is as follows. The date palm has been a source of inspiration for architects in Iraqi architecture throughout the ages. The research will depend on the inductive approach in order to read the effect of date palm morphology on the design of Iraqi architecture. In the current study, the focus will be on the references that identify the relationship of metaphor to the design process and its relations to the various aspects and issues related to installation phase and ideas generated during the design process.

\section{CATEGORIES OF THE METAPHOR}

The role of the architectural designer within the design process is to evoke a specific reference that provides design decisions in each stage of this process to organize the elements of architecture production based on the relationship of that reference with the required meaning. Three broad categories of metaphor can be identified.

Intangible metaphors are those in which metaphorical aspect for the creation is a concept, an idea, a human condition, or a particular quality (individuality, naturalness, community, tradition, and culture).

Tangible metaphors are those in which metaphorical aspect stems strictly from some visual or material character (a house as a castle, the roof of a temple as sky).

Combined metaphors are those in which the conceptual and the visual aspects overlap as ingredients of the process of creation, where the visual aspect detects the virtue, the qualities, and the fundamentals of the particular, visual container (the computer, the beehive, both being "boxes" of relevant proportions, yet having the qualities of discipline, organization, and cooperation) (Antoniades, 1990).

There is a definition to metaphor by noting we all perform acts whenever we do the following:

- $\quad$ attempt to transfer references from one subject (concept or object) to another;

- attempt to "see" a subject (concept or object) as if it was something else;

- displace the focus of our scrutiny from one area of concentration or from one inquiry into another (in the hope that by comparison or through extension we can illuminate our contemplated subject in a new way) (Al-Jameel, 2012).

The metaphor is related to the issue of innovation and changes in architectural ideas. So, the metaphor is important for how these changes occur for reasons related to conceptual change process. Able has addressed this issue when he highlighted the most important aspect of metaphor: "its dynamic role in making us see something through something else, in a new way for us". Metaphor for him is the process by which all new ideas come into 
existence (Able, 1982). While Collins pointed out that "the similarity of architecture to the biological world was defined by four common features": the relationship between living systems and their environment, the linking between members, relationship of form with function, and principle of vitality (Collins, 1965). So, the studies dealing with metaphor in architecture include a number of particular aspects of this concept. In general, these studies highlight four main aspects about the concept of metaphor in architecture: goal of metaphor, motive of metaphor, source of metaphor, relationship of metaphor. Therefore, in all cases, the metaphor is of two types (AlJameel, 1996):

- $\quad$ direct metaphor;

- $\quad$ indirect metaphor.

\section{BIO-METAPHOR IN ARCHITECTURE}

Architecture has long been derived from nature as a source of inspiration. Vital morphology isthe integration of existing natural elements as inspiration source in design. The ancient Greeks and Romans incorporated natural forms into the design such as the tree-inspired columns, or from human body, like a Corinthian column whose head was borrowed from acanthus plant, Figure 1.
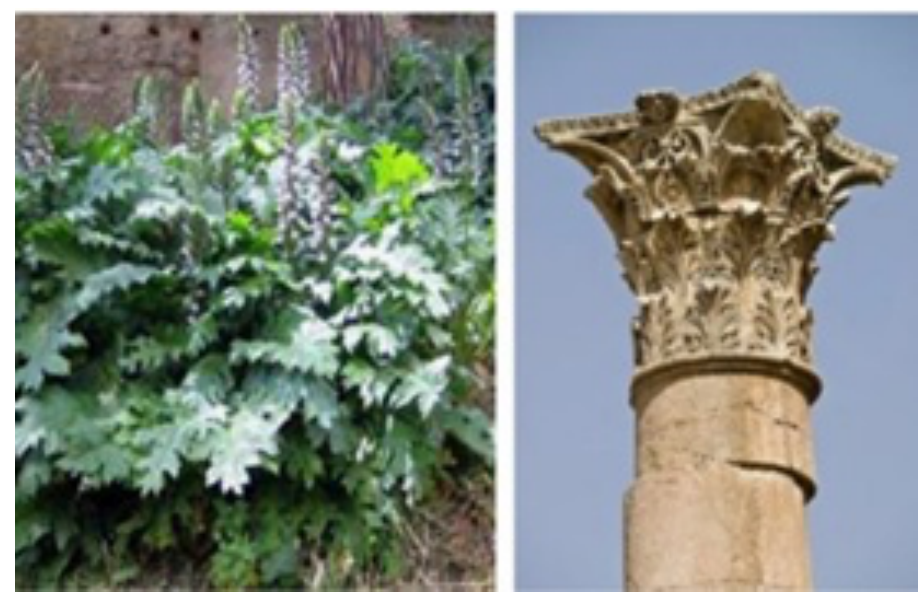

Figure 1. Acanthus plants; Corinthian column head. (Aziz, 2015).

The metaphor from any organism is a metaphor for a particular aspect in it. This aspect may be the form of the organism or the way the organism performs a function. It is referred to the side from which it is metaphoring the "level of bio-metaphor". Nature metaphor levels had been classified by Janine Benyus into three levels that can be applied when addressing a design problem: form, vital process, and ecosystem (Janine, 2002). While Pedersen Zari classified the levels of bio-metaphor into three levels: Organism, behavior, and ecosystem levels.

The organism level refers to a specific organism like a plant or animal and may involve metaphor of a part of or the whole organism. The second level refers to metaphor behavior and may include translating an aspect of organism behavior into organic design, or relationship to a larger context. The third level is the metaphor of whole ecosystems and the common principles that allow them to work successfully, or their actual functions (Pedersen, 2012).

According to the above, the categories of bio-metaphor can be explained in detail as follows, 
Organism level: on this level, the architecture looks to the organism itself, applying its form and/or functions to a building (Pedersen, 2015). This type of metaphor can be seen in Oriente Station, Lisbon, designed by Santiago Caltrava in 1993. The steel ribbed dendriform not only acts as a structural support, but also forms a roof canopy. In this case, the steel ribbed canopy bears a strong resemblance to a grove of palm trees. Also it is seen in Sagrada Familia cathedral 1882, by Antonio Gaudi Barcelona, where the columns are inclined and branched-like trees, so the weight was routed directly over the pillars in the ground, all this without bearing façade or exterior buttresses, see Figures $2 \& 3$.

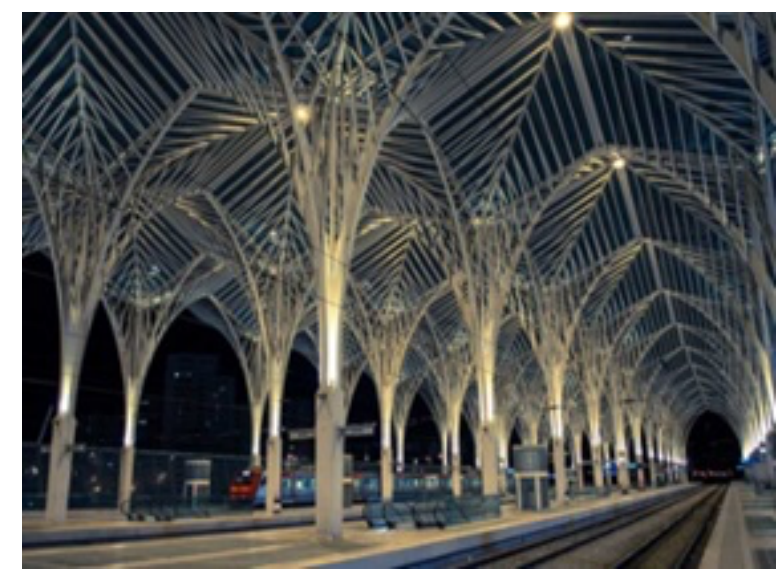

Figure 2. Oriente Station, Lisbon (Kennedy, 2016).

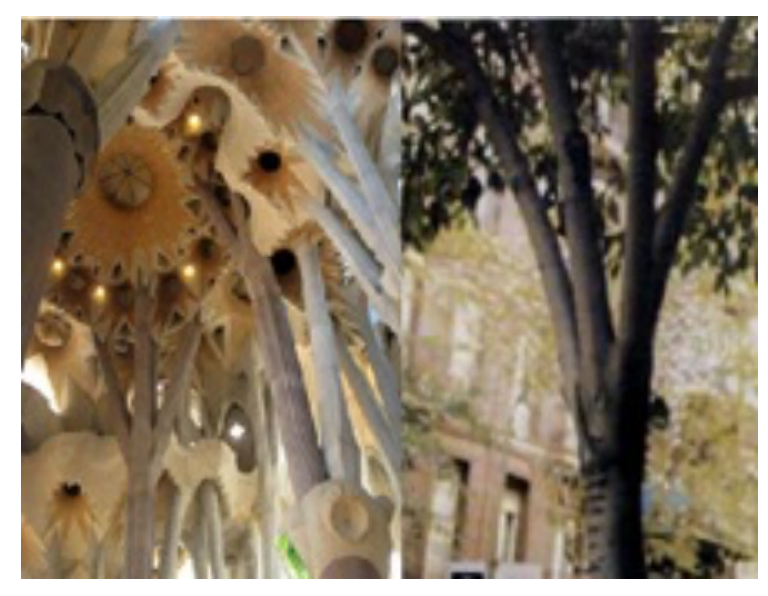

Figure 3. Sagrada Familia cathedral

Behavior level: on this level, the building metaphor reflects how the organism interacts with its environment to build a structure that can also fit in without resistance in its surrounding built environment. This type of metaphor can be seen in Hydrological Center, Namibia, exploration, by the architect Matthew Parkes. A metaphor of the ladybug started tilting its body into the wind so that water will be stored in the center by intensifying the morning fog on a nylon sail was metaphored from this ladybug (Eid \& Sabreen, 2018). Also, this type of metaphor is within Arab World Institute building by Jean Nouvel, Paris, 1980. The building directed to the south is an adaptive façade full of mechanical diaphragms linked with the construction brain which coordinates devices that open and close creating shade for the interior, like the mechanism of human eye work; see Figures 4 \& 5 . 

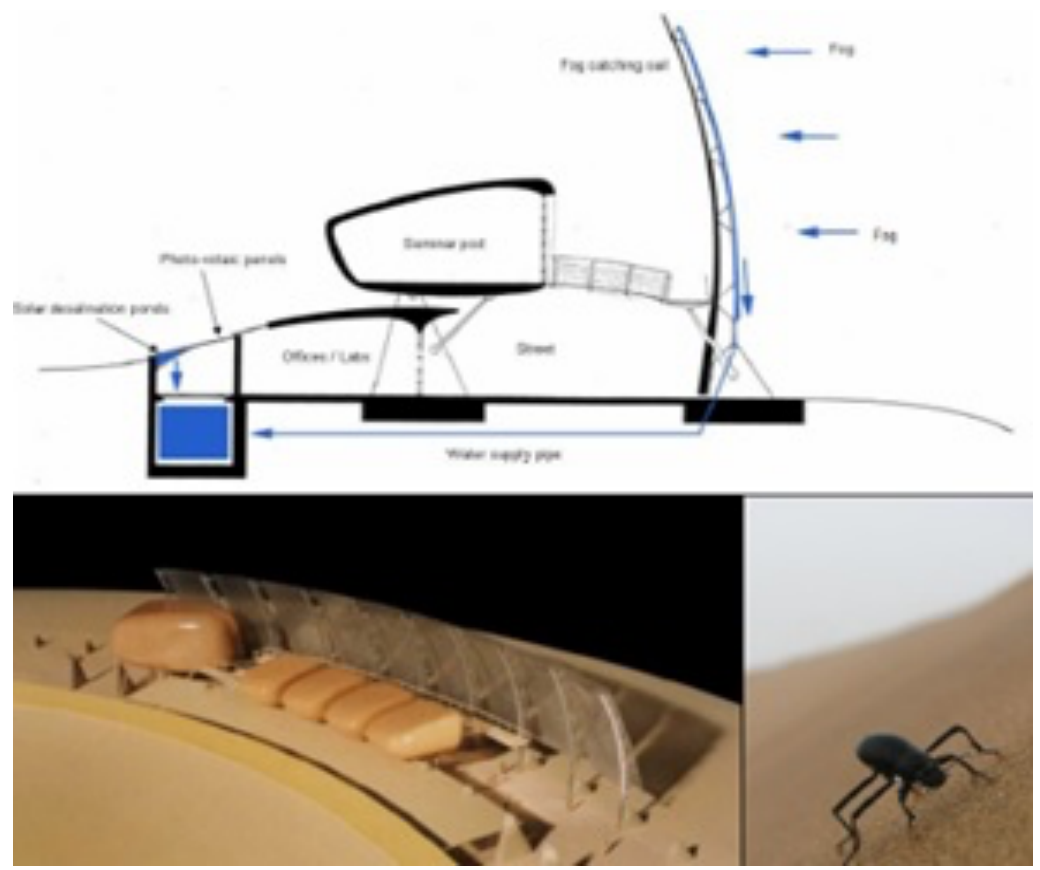

Figure 4. Hydrological Center, Namibia.) (Pedersen, 2012).

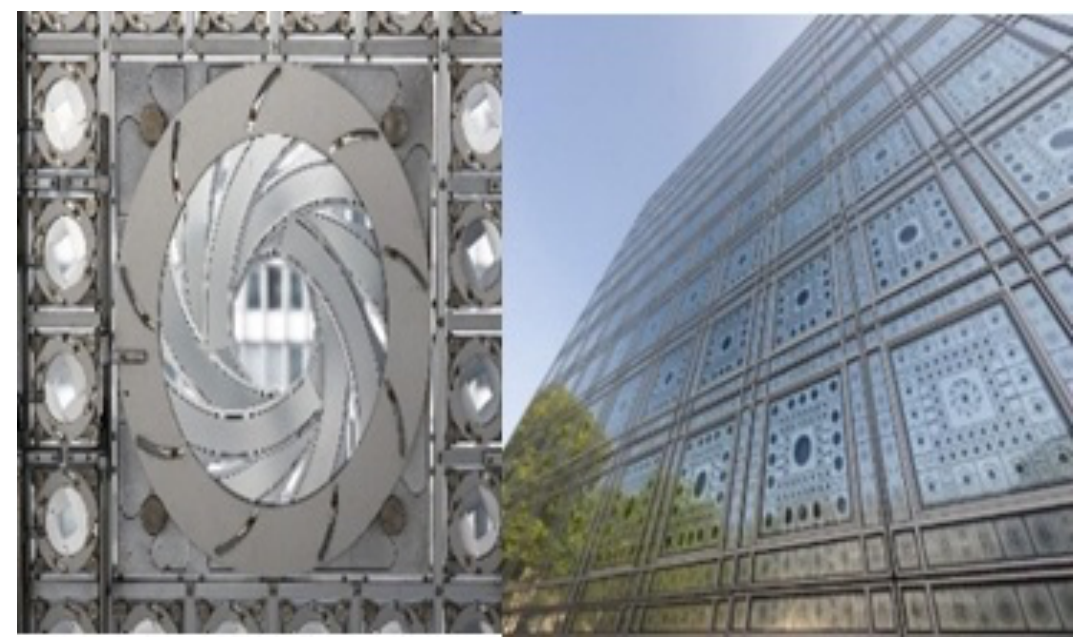

Figure 5. Arab World Institute, Paris (Al Ani, 2011)

Ecosystem level: this level involves metaphor of how the environmental components work together and work to be on the urban scale or a larger project with multiple elements rather than a solitary structure (Michael, 2011).Treescraper Tower of Tomorrow by William McDonough, 2007, represents this type of metaphor. This building imitates a tree in its ecosystem, producing energy and changing with seasons. The aerodynamic shape of the building reduces the impact of the wind and reduces the amount of materials needed for construction, which increases structural stability, creating a building that makes oxygen, distills water, and changes with the seasons, Figure 6 . 


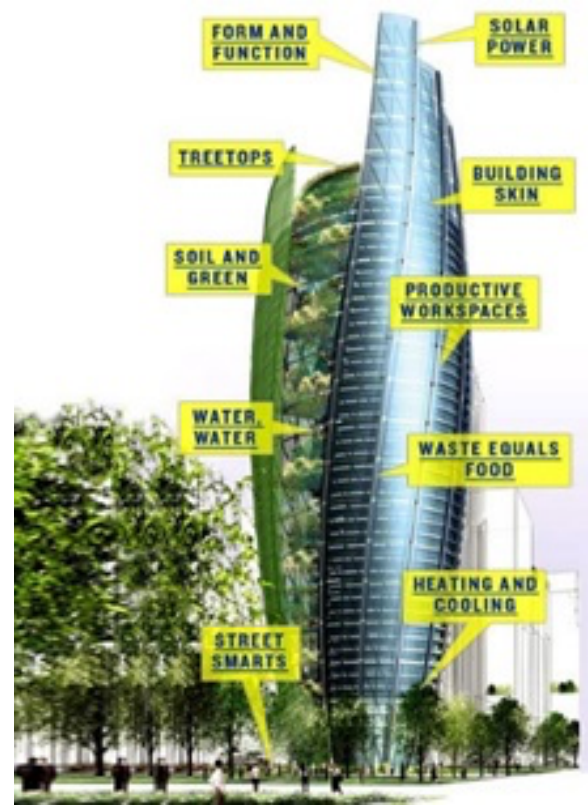

Figure 6. Treescraper Tower of Tomorrow (Michael, 2011).

The strategy of bio-metaphor consists of several approaches based on the natural forms, concepts and principles that shape them, and the structural systems that exist. Designers have dealt with nature in different ways through form (Sate'\& Mumtaz, 2008). The form comes in several formulas including shape, image, type, and structure. Thus, the form is the homogeneous structure, in which the number of perceived elements is associated with appropriate relationships to recognize the personal qualities of the mind that produces it, and those relationships are (construction, configuration, arrangement, and organization) (Blake, 1976). The forms in nature are divided into the following:

- $\quad$ Living natural forms are divided into animal form and plant form.

- The non-living forms include everything that exists in nature except living organisms, such as desert sand, mountains or ice crystals, and so on (Whyte, 1968); see Figure 7.

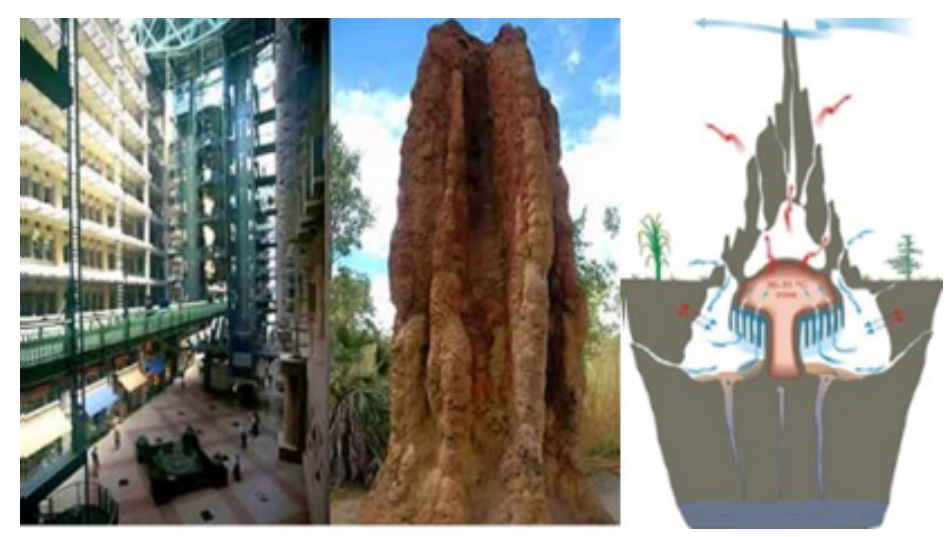

Figure 7. Eastgate Harare Center, Zimbabwe. 
The types mentioned for metaphor represent the theoretical framework indicators for this study, on which the research will rely in the practical study.

\section{DATE PALM MORPHOLOGY}

Date palm is a monocotyledon plant with a single stem and dioecious, and it has a single growth inside the trunk in the top of tree. The length of the trunk increases until it reaches about $24 \mathrm{~m}$. As the leaves resemble pinnate, the length of one leaf ranges between 240 - and $370 \mathrm{~cm}$. (Sharqiah, 2020).

This tree belongs to Palmae, which is considered one of the most important and famous plant families. Its family contains different numbers of genera, which in turn contain more than 4200 species of palms. Date palm belongs to the genus Phoenix, which includes several types. The most important species close to the date palm are the following (Hussam, 2015):

- $\quad$ sugar palm (Phoenix sylvestris L.),

- $\quad$ canary palm (Phoenix canariensis L.),

- date palm (Phoenix dactylifera L.). All of these types consist of the following parts: -

- $\quad$ crown leaves, leaves, fruiting zone, trunk, rachis base, and root zone ${ }^{1}$. See Figure 8.

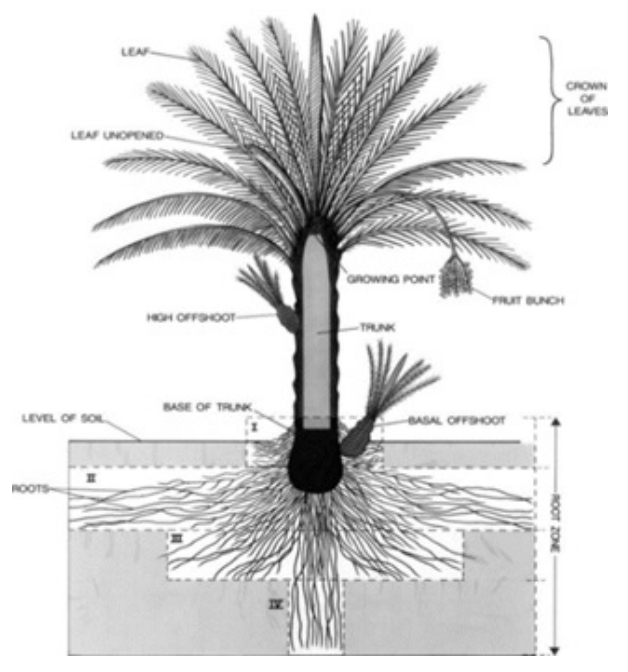

Figure 8. Parts of a date palm (Chao, 2007).

\section{THE IMAGE OF THE PALM IN MESOPOTAMIAN CULTURE}

The date palm occupied a special place not only in ancient Iraq, but also in other civilizations till this day. Date palm is one of the most important trees that symbolize life. The Sumerians called it (gish-shir-gal) which means the great tree. This palm tree is symbol of Tammuz, the fertile god according to the myth of Ishtar and Tammuz (PASZKE, 2019). The date palm (Phoenix dactylifera L.) is one of the oldest cultivated fruit trees and was

1. For more information about the morphology of the date palm, see the following source (Date palm / its past and present, and new in its cultivation)- Author: Abdul-Jabbar Al-Bakr. 
well known in Mesopotamia (Iraq) Specifically Sumerian era (4000 B.C). People were heavily dependent on this tree to provide food and wood for making tools, furniture, and baskets (Al-Khayri, 2015).

New trends have emerged in artistic productions especially during the Jumadat Nasr era, the first great art of the stately temple architecture emerged, as well as all the arts that were found essentially for his service. The art became the expression of the lofty concept of God and the King (Al-Khayri, 2015). In general, the plant decoration flourished, and the artist benefited from nature in all its kinds and forms, including the palm, which represented the best representation in the ancient Iraqi arts. The Sumerian artist portrayed the palm and used it extensively with God and the King, a symbol of his religious beliefs and intellectual and political circumstances (Al Yawar, 2003). In the models during the Sumerian-Akkadian period, the palm tree and its fronds had appeared in their arts. In the Stela of Ur-Nammu, the palm fronds appeared in a religious scene; see Figure 9.
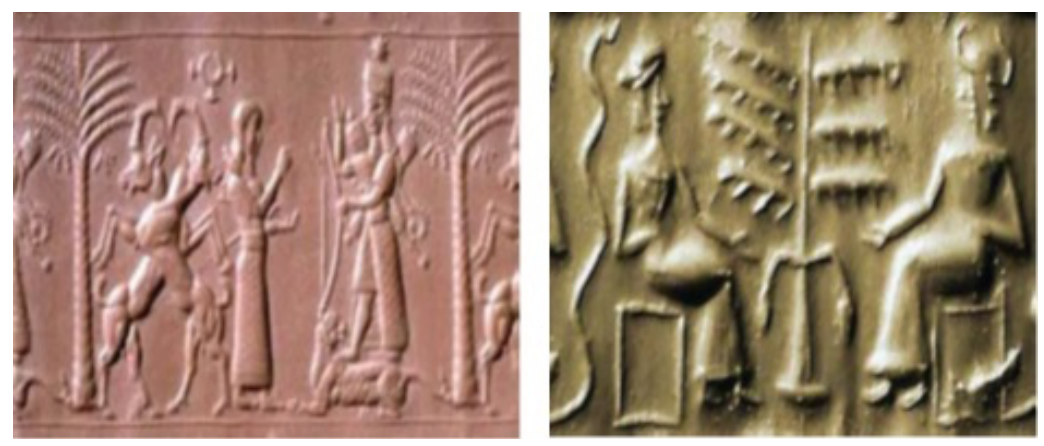

Figure 9. The blessed date palm in the Sumerian era (Al-Khayri, 2015).

The palm tree in Mesopotamia has been considered the most important symbol of the sign of life and continuity. It has been featured in many myths in Mesopotamia, which refer to fertility and life, such as myth of Inana and Shocaltoda (Abu Khudair, 2016).

The artist tried to metaphor from nature; the Babylonians inherited a heritage derived from Sumerian architecture and arts such as the palm that was considered the tree of life. In the entrance of throne hall in modern Babylon era, we can see the palm directed upward and based on number of lions which refers to the underworld from which life explodes (Abu Khudair, 2016). See Figure 10.

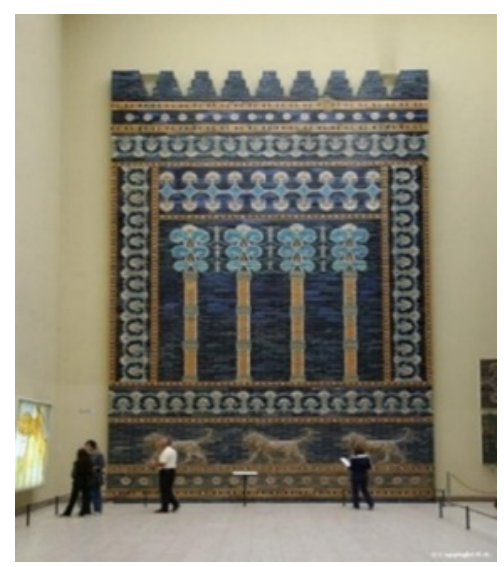

Figure 10. The date palm on entrance of throne hall in modern Babylon era (researcher). 
In the Assyrian civilization, the most common theme was the decoration of the trees, which was essential. The palm tree is inspired from Iraqi nature and it is familiar in most scenes of Sumerian and Babylonian art and is taken by the Assyrians as well. It symbolized the authority and the dominant power in life (Giovino, 2007) (Al-Assadi\& Al-Dewachi, 2020); see Figure11.

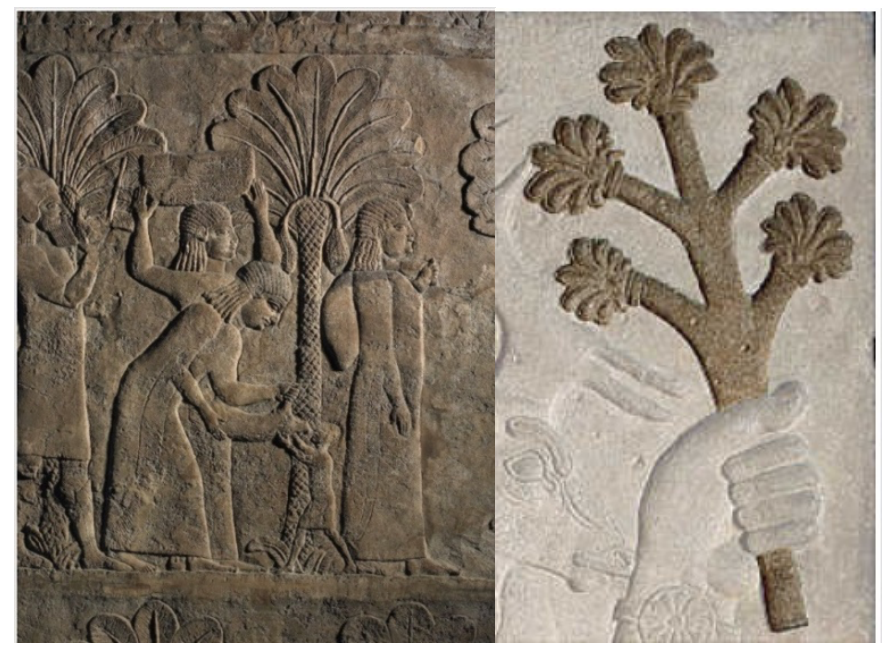

Figure 11. The sacred tree in Assyrian mythology is a palm that symbolizes Ishtar connecting heaven, the crown of the tree, and earth, the base of the trunk.

https://allmesopotamia.wordpress.com/2018/01/28/dates-in-mesopotamia/

In Islamic religion, god raised the value of the palm and placed its blessed fruits in a special place among the rest of the trees and mentioned in many of the Surahs in the Holy Quran, including Al-An'am, Al-Kahaf, Taha, Alqamar, Al-Rahman, and Al-Haqqah and made them fruits of paradise like figs, olives, pomegranates, and grapes, as mentioned in the Hadith in many places; dates have a special place in people's lives; it is food and medicine (AlSamaraie, 2009).

It is noteworthy that the new artistic style was spread in Islamic art, characterized by the emergence of the Palm fronds that were found in the mehrab Al-Khasaky, Figure12.

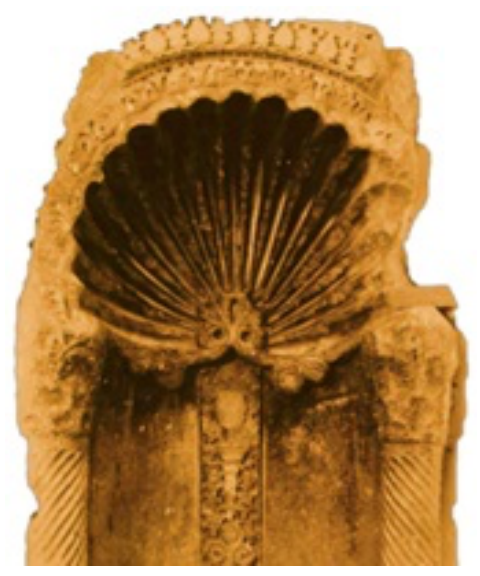

Figure 12. The palm in Islamic art. Al- Khassaki mehrab mosque (Alwaily, 2017). 


\section{RESEARCH OBJECTIVE AND METHODOLOGY}

The objective of this research is to know the impact of the form of date palm tree on the thought of Iraqi architects, thus a product of Iraqi architecture through the ages.

In the current study, the focus will be on literature review that defines the relationship of metaphor to the design process, its relationships with different aspects, issues related to the installation stage, and the ideas generated during the design process.

The main question in the study is the following. How is the application of the metaphor analyzed in Iraqi architecture through the ages? To reach an answer, the research will follow the descriptive approach based on the inductive procedure approach, to see the effect of palm morphology on the design of Iraqi architecture. It provides a new theoretical horizon for a better understanding and serves as the essential of the understanding of the physical image of the metaphor. Therefore, the investigation is an attempt to initiate an effective link between the design process and architectural principles to develop an approach that draws inspiration from the local elements, applied in contemporary architectural productions.

In the practical application of this study, the indicators reached in the theoretical part will be applied, in order to arrive at how to apply the biological metaphor of the date palm to Iraqi architecture through the ages down to contemporary architecture, through a study of buildings for the Sumerian, Babylonian, and Assyrian period, down to contemporary architecture. The following flowchart shows the methodology of the practical study.

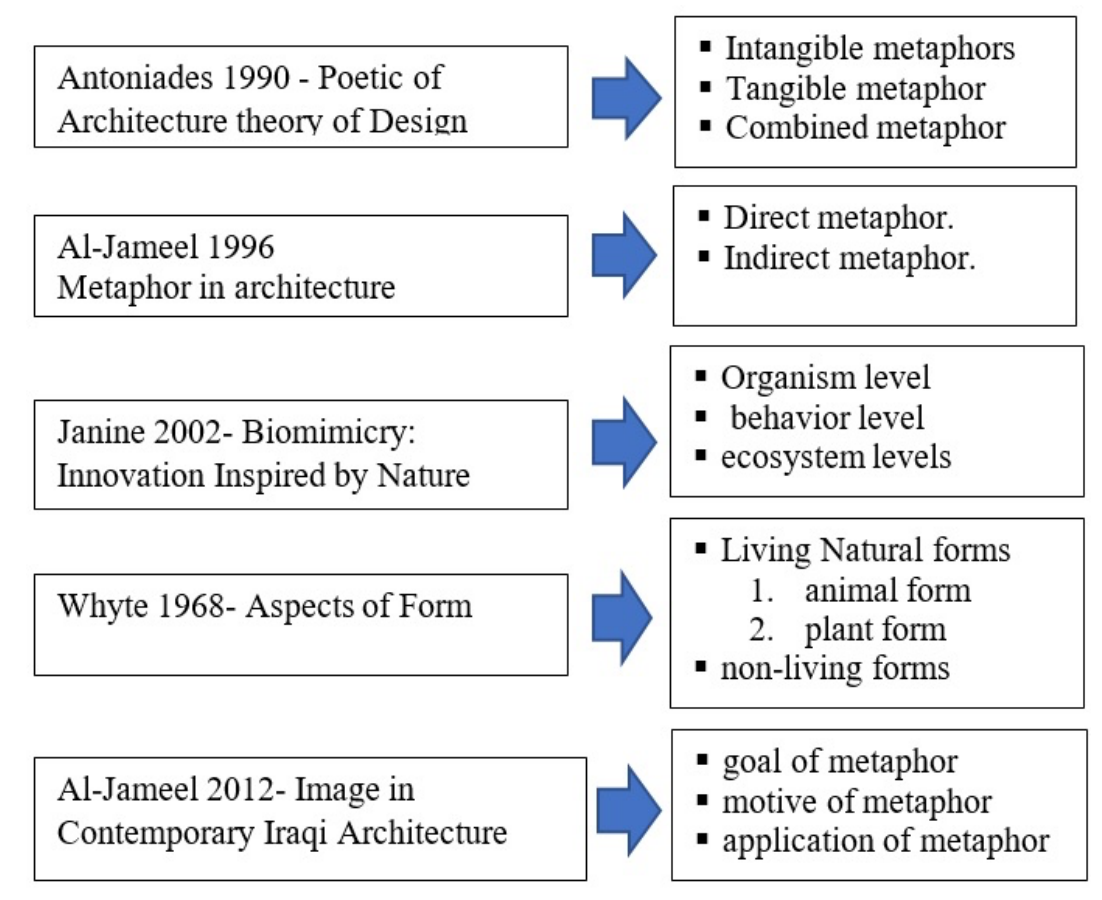

Figure 13. Flowchart shows the methodology of the practical study (researcher).

Based on the indicators that the research extracted from the theoretical part, which is shown by the above chart, the research deduced the practical study table, which will be applied to the case studies. 
Table 1. The practical application table of the search (researcher).

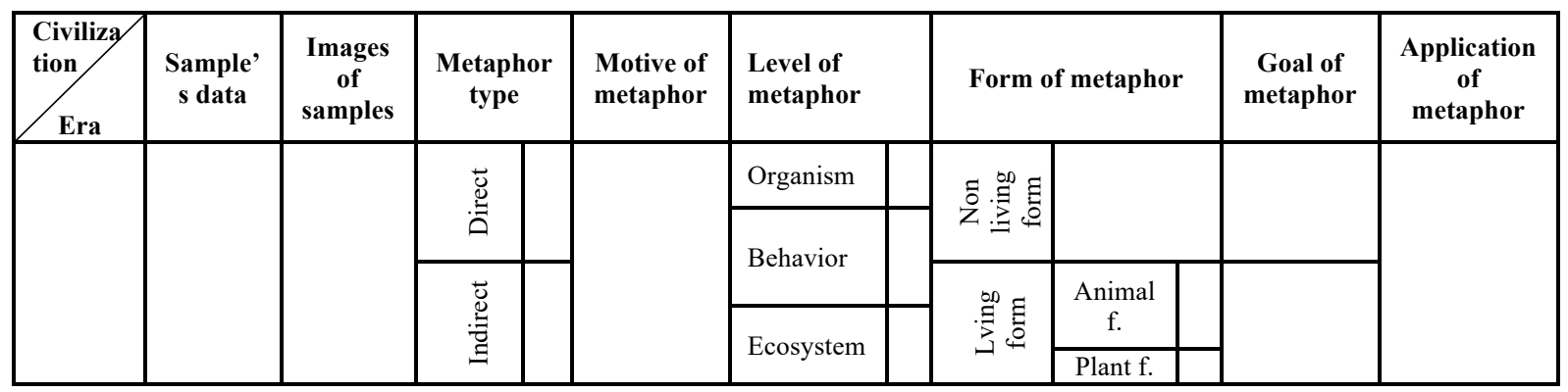

The table includes the most important indicators drawn from previous literatures, which include the type of metaphor, its level, motive of metaphor, the source of metaphor, form of metaphor, the purpose of metaphor, and its application, applying these indicators to samples of building for different eras of Iraqi architecture, to find out whether the Iraqi architecture was inspired from the palm tree for its architectural product or not, how to apply the metaphor, thus achieving the aim of research and verifying the hypothesis that was referred to previously.

\section{PRACTICAL APPLICATION/ METAPHOR OF DATE PALM IN IRAQI ARCHITECTURE}

The civilization of ancient Iraq (Mesopotamia ${ }^{2}$ ) emerged in the third millennium BC under the shadow of the Sumerians and Akkadians and reached its climax in the second and first millennium BC, the days of the Babylonians and Assyrians (Moortgart, 1975).

It is the site of the earliest developments of the Neolithic Revolution from around 10,000 BC to the fall of Babylon in $539 \mathrm{BC}$. It is the region within the Tigris and Euphrates rivers, (Iraq currently). Mesopotamia is the site of the earliest developments of the Neolithic Revolution. It has been identified as having inspired some of the most important developments in human history, including the invention of the wheel, and the development of cursive script, mathematics, astronomy, and agriculture. It annexed the earliest greatest civilizations, which bequeathed the earliest forms of organized government, religion, warfare, architecture, and literature (Youssef, 1982).

This paper will shed light on metaphor from date palm in Iraqi architecture for different periods of Iraqi architecture starting from Mesopotamia to contemporary Iraqi architecture because of the importance of this tree in the Iraqi civilization in all historical eras, as we have shown. The selection of study samples will depend on the chronology of Iraqi architecture, starting with the Sumerian, Babylonian, Assyrian, and Islamic architecture, up to contemporary Iraqi architecture. Table 2 shows the practical study of this research.

\footnotetext{
${ }^{2}$ Mesopotamia meaning "between rivers," referring to the land between the Tigris and Euphrates rivers (Iraq currently) (https://www.britannica.com/place/Mesopotamia-historical-region-Asia).
} 


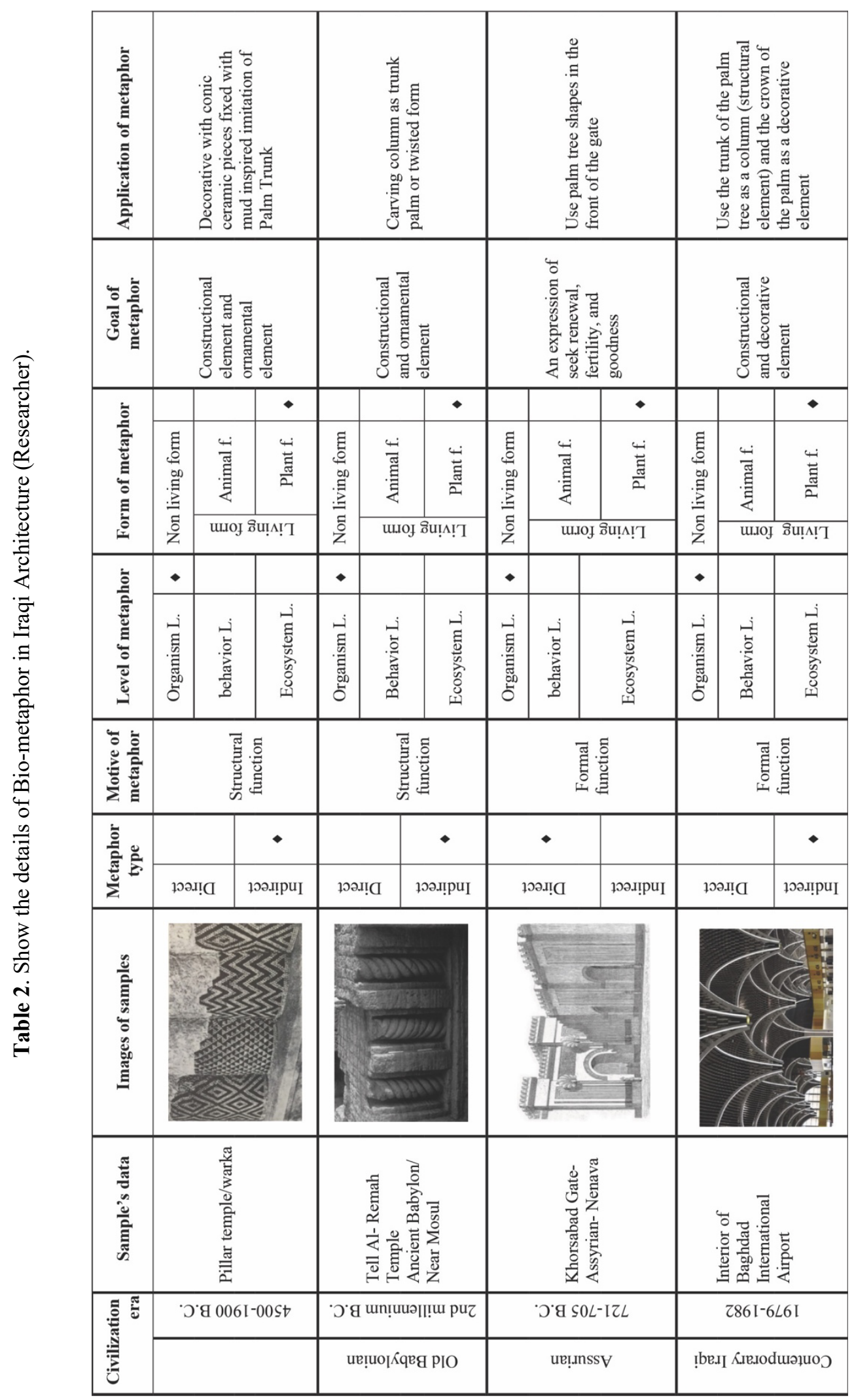




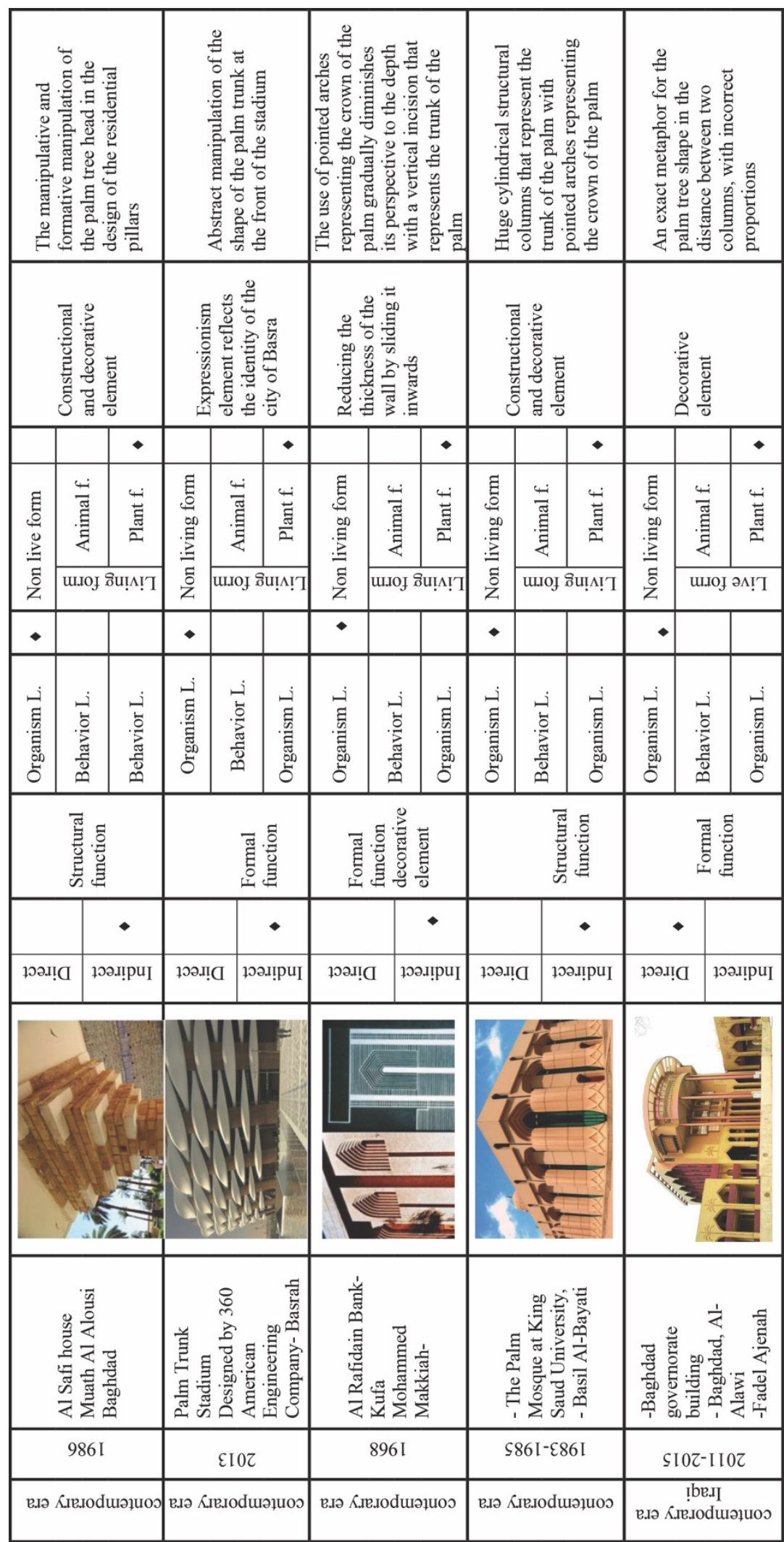




\section{DISCUSSION}

The metaphors varied in Iraqi architecture between direct and indirect. Even the direct method has varied between the exact literality metaphor of the palm tree, or picking out a part of it and applying it to the building. The research found that partial indirect metaphor is morphologically stronger than total direct one, because it gives the recipient the ability to interpret the resulting form which gives the architectural a product of distinctive aspect, structurally and formally. Regarding the motive of the metaphor, the metaphor with a constructional impulse is stronger than the one with morphological one, because the form (the part picked out from the palm tree) in the first case is inherent in the building. It is part of the building's basic composition. As for the metaphor of morphological motive only, it was used for decorative purposes only. It is not part of the building's basic composition. Here, the research reaches to verify the research hypothesis through the fact that the date palm tree has been a source of inspiration for architects in Iraqi architecture through the ages and via several levels:

- Indirect partial metaphor,

- Direct total metaphor.

The aim and hypothesis of research were achieved by proving that the date palm tree was a source of metaphor in Iraqi architecture throughout the ages.

\section{CONCLUSIONS}

1- Bio-metaphor is a simulation of nature through its distinctive characteristics achieved for its performance efficiency, which is characterized by flexibility, vitality, balance, and adaptation, achieved at the level of form and physical formation involving the envelope, structure and its parts, and the level of functional behavior.

2- Designing bio- metaphor is a bridge that can deliver architecture and design by linking design to the environment via advanced technology.

3- Bio-metaphor is not a new innovation. It is a continuous phenomenon, and architects throughout the ages have consistently included their productions. It began with simulating the formal aspects and extended to the functional commons, right up to the inspiration of the integrated system that indicates form, behavior, and beauty through technological developments and their impact in the field of design process.

4- Bio-metaphor emphasized the importance of building integration with the environment. It should be expressed on it, but is not limited to formal treatments, and it is not limited to formal processors via symbols and details. It has a deep understanding of the various characteristics of the environment (environmental / social, functional, and so on).

5- The exterior of the building, which represents the facade of the building, expresses the inspiration of the living skin, the skin, plant crust ... ". It represents the most important part in bio-metaphor architecture to represent an integrated, responsive, interactive, and adaptive system by the formation and intelligent materials put forward by advanced technology.

6- The palm was associated from the beginning with religious and environmental beliefs. The Mesopotamian's artist and architect has clearly benefited from the creation of new forms inspired by the form of palm tree.

7- The palm tree had a paramount importance to the lives of ancient Iraqis. It is the source of wealth and linking to the land and rooting in it, so it has become one of the important symbols that have become a source of biological metaphor in Mesopotamian architecture and till now.

8- Bio-metaphor used palm tree in different ways and methods including structural and decorative. The palm trunk was metaphored in form of a structural column or its crown for decorative and structural purpose. 


\section{REFERENCES}

Able, C., 1982. The role of metaphor in changing architectural concepts in "Changing Design",Edited by B.Evans,J.A.Powell, and R.J.Talbot, John Wiley \&Sons Ltd. Pp.334-335.

Abu Khudair, K., 2016. Symbolism in religious thought in the civilization of Mesopotamia and civilization of Iran in thepast. Magazine of historical studies and archaeology, issue 55. Pp 443-500.

Al-Akidi, H., 2010. Date Palm the lady of trees and pearls of fruit. Dar Amna for Publishing \& Distributionp.137.

Al-Ahmar, S. 2010. Biomimicry as a Tool for Sustainable Architectural Design: Towards Morphogenetic Architecture.(master's thesis) Alexandria University.

Al Ani, M., 2011. Urban Prediction- Towards a new Generation to Redevelop the Arabic- Islamic City. Un published doctorate thesis, Baghdad university.

Al-Assadi, F. and Al-Dewachi, M. 2020. The Role of Brick in Determining Features of Iraqi Architecture. IOP Conf. Series: Materials Science and Engineering881 (2020) 012018 doi:10.1088/1757-899X/881/1/012018

Al-Jameel, A. 1996. Metaphor in architecture. Phd thesis,college of engineering the University of Technical, Iraq, Pp 54.

Al-Jameel, A. \& Al-Nima, M. 2012. Image in Contemporary Iraqi Architecture. Al-Rafidain Engineering journal, Vol.20, issue no.1. Pp 37-57.

Al-Khayri, J. \& Jain, Shri M. 2015. Date Palm Genetic Resources and Utilization. Springer Dordrecht Heidelberg NewYork London. Pp 98-100.

Al-Samaraie, M., 2009. Palm in the Mesopotamian civilization in Iraq. Research published in Khalifa International Award for Date Palm. P.4.

Alwaily, T., 2017. 21st Baghdad- Revival of historical city. Dar Al-Adeeb Press, Amman. P.26.

Al Yawar, T., 2003. Palm Tree in the Arabic \& Islamic Art, published research, https://www.abualsoof.com/INP/Upload/Books/Palm-in-Arabic-Art-and-Islam.pdf.

Antoniades A., 1990. Poetic of Architecture theory of Design. Van Nostrand Reinhold N.Y. U.S.A. Pp. 29-30.

Aziz, M. \& El sheriff, 2015. A. Biomimicry as an approach for bio-inspired structure with the aid of computation, Alexandria University, Faculty of Engineering, Architectural department, Egypt. P.4.

Blake, P., 1976. The Master Building. New York : W.W. Nordon \&Company, Inc. p.3.

Calatrava, S., calatrava.com/projects/oriente- station-lisboa.html

Collins, P. 1965. Changing Ideals in Modern Architecture. 11750-1950, Faber and Faber, London. P. 93.

Chao, C. \& Krueger, R., 2007. The Date Palm (Phoenix dactylifera L.): Overview of Biology, Uses, and Cultivation. HORTSCIENCE, Volume 42: Issue 5. Pp. 1077 \& 1080 
Eid, S. \& et.al, 2018. Simulating the natural environment to achieve thermal comfort in the desert environment. The ThirdInternational Conference: Creativity, Innovation and Development in Architecture, Heritage, Arts and Literature "Future Visions in the Civilizations and Cultures of the Arab World and the Countries of the Mediterranean Basin" Alexandria.p437

Giovino, M., 2007.The Assyrian Sacred Tree: A History of Interpretations. Zurich Open Repositoryand Archive, University of Zurich. p271

Greene, H., 1976. Mind \& Image. The University of Kentucky Press, Lexington ,KY. P109.

Gruber, P. 2011. BIOMIMETICS IN ARCHITECTURE- ARCHITECTURE OF LIFE AND BUILDINGS. Strauss GmbH, Mörlenbach, Germany. Hussam, H., (2015). Plant classification, morphological description and anatomical structure of date palm. Error! Hyperlink reference not valid..

GECAS, S., 2014. BETWEEN SYMBOLISM AND METAPHOR. journal of ARCHITECTURE AND URBANISM ISSN 2029-7955 / EISSN 2029-7947.2014 Volume 38(4):283292doi:10.3846/20297955.2014.999432

Janine, B., 2002. Biomimicry: Innovation Inspired by Nature. Publisher: Harper Perennial.P10.

Jill F., (2012). Biomimetic Architecture: Green building in Zimbabwe Modeled after Termite Mounds. Inhabitat, last modified November. http://inhabitat.com/building-modelled-on-termites-eastgate-centre-inzimbabwe.

Kennedy, E. B., 2016. Biomimetic buildings: The Emerging Future of Architecture. University of Akron, GBER Vol 10 Issue 1. P8.

McGinty, T., 1979. Concepts in Architecture, in Snyder, J., \& Catanese, A., (Eds). P228.

Michael P., 2011. Biomimicry in Green Design: From Theory to Practice. Edited by Ken Yeang andArthur Spector, London: Black Dog. P37.

Moortgart, A., 1975. The Art of Ancient Mesopotamia. Translated and commented by Dr. Issa Salman and Salim TahaAl-Tikriti, Ministry of Information, Directorate, General Culture, Baghdad,Al-Adeeb AlBaghdadia Press. P230.

PASZKE, M. DATE PALM AND DATE PALM INFLORESCENCES IN THE LATE URUK PERIOD (C. 3300 B.C.): BOTANY AND ARCHAIC SCRIPT. 81 221-239 Doi:10.1017/irq.2019.15. Pp.221-239.

Pedersen Z.,2012. Ecosystem Services analysis for the Design of Regenerative Urban Built Environments. Published thesis, Victoria University of Wellington. P105.

Pedersen Z, 2015. BIOMIMETIC APPROACHES TO ARCHITECTURAL DESIGN FOR INCREASED SUSTAINABILITY. School of Architecture, Victoria University. P7.

Sate' S. \& Mumtaz, R., 2008. The nature imitation strategy and the sustainable architectural form: analytical study for organic forms through the architectural product of Eguen Tsui. Published research in Iraqi Journal of Architecture, Volume 4, No. 12-13.

Sharqiah, A., 2020. Encyclopedia of Pictured Palm. Published book on internet. https://www.noorbook.com/pdf. P92. 
Whyte, L., 1968. Aspects of Form. Lund Humphries,Lund Humphries; 2nd edition London. P 46. ISBN-10 :0853310076. P 119.

Youssef, S.,1982. History of Iraqi Architecture in Different Ages. Ministry of Culture and Information Publications, Dar Al-Rasheed Publishing, Iraq, Arabic Series.P162. https://allmesopotamia.wordpress.com/2018/01/28/dates-in-mesopotamia/ https://www.britannica.com/place/Mesopotamia-historical-region-Asia/ 